\title{
Importance of Quality in Medical and Dental Institutes
}

\author{
Kiran Fatima Mehboob Ali Bana, Nadia Khalid, Wahab Kadri
}

\begin{abstract}
:
There is a dire need to incorporate quality improvement measures in medical education of our country as now worldwide the paradigm is shifted from the students' outcome to the continuous quality improvement (CQI) measures. The ultimate goal of CQI is to provide optimal patient care. This is the responsibility of the accreditation council (PMDC) to ensure the true application of quality improvement indicators in medical institutes. The quality document introduced by the PMDC is the true reflection of the world accreditation bodies WFME, WHO. By ensuring the true application of this quality document, Pakistan Medical and Dental Council will be able to compete with the International standards of medical education through competent future physicians.
\end{abstract}

Key words: Accreditation, quality, quality document.

\section{INTRODUCTION:}

"A physician who is excellent academically with the science of medicine but incompetent in the art of medicine due to lack of experience and updated knowledge is like a one winged bird who is inept to fly high in the sky". (Shushruta Samhita 300-400 BC3)

The profession of physician is the most respectful in every era of mankind. For the sake of credibility of this relation, it is imperative to be skilled and updated. This is difficult to establish direct link between the education quality and accreditation. $^{2-7}$

The political, social and economic challenges have poorly impacted the quality of medical education in our country, so this is the time to revise and reassure the true application of the quality standards ${ }^{1,8}$ to face these challenges by ensuring optimal patient care. ${ }^{2}$ The accreditation body of the country is sole responsible to bring the quality standards, framework and professional guidelines in medical education to shape the physicians of today and tomorrow. ${ }^{1}$

Quality is a subjective and vibrant term so a bit difficult to express and has multiple meanings for various stakeholders. In medical education, quality is defined as "to adapt certain standards in medical education approved by an accreditation council or an external agency"1

Moreover, quality in education is defined as value for money to reach certain bench marks. Quality can be estimated by

Kiran Fatima Mehboob Ali Bana
Senior Lecturer, Department of Community Dentistry.
Bahria University of Medical and Dental College, Karachi
Email: kiranbana291@gmail.com
Nadia Khalid
Senior Lecturer, Department of CHS
Wahria University Medical and Dental College, Karachi
Principal (Dental Section), Professor and HOD OMFS Dept.
Rahria University Medical and Dental College, Karachi
Acceived: $26-02-19$

number of quality researches in an educational Institute. ${ }^{8}$

Furthermore, quality in education is the achievement towards mission and vision of an Institute. ${ }^{9}$

\section{Quality in medical education.}

The purpose of considering quality in medical education in Pakistan is to develop the today's and future doctors as a competent healthcare personnel. It is already emphasized in 'Tomorrow's Doctor'; that there is an emerging need to develop a framework to ensure the quality and competency among future physicians. ${ }^{9}$ This framework should reflect the bench marks and standards approved by the WFME (World Federation of Medical Education) and the WHO (World Health Organization). ${ }^{2,10}$ These are the international accreditation agencies of medical education. Quality in Medical Education is a growing demand of all the stakeholders due to following reasons. ${ }^{2,10}$

( To ensure that the students admitted in the Institute will become competent after qualifying.

( The future doctors would be able to compete with the international standards of medical education.

( The institutes have to accomplish and adopt the criteria of an accreditation council.

The PMDC council is the accreditation body in Pakistan. To compete with the world standards of Medical Education, it has formulated the quality document approved by the WFME by the help of the competent team of medical educationalist which then followed and adopted by the entire medical Institutes of Pakistan. The core outcome to bring quality in medical education is patient centered care. , 10-12 $^{\text {12 }}$

\section{Quality document of PMDC:}

Following factors are considered by $\mathrm{PMDC}^{13,14}$ while formulating the quality document for medical colleges of Pakistan. This quality document is addressing the core competencies of the physician as prescribed by WFME.

(- To ensure the homogenous training of future physicians.

u To establish the transparent mode of entrance examination.

(- Development of centrally regulated curriculum. 
( Predefined framework of self evaluation and academic audit conducted within Institute and for external audit.

- To enhance teaching strategies which make the future doctors a critical thinker, problem solver, decision maker and overhaul a competent healthcare provider.

( To ensure the transparent induction of qualified teachers in medical and dental Institutes.

口 There should be well established department for monitoring and evaluation which ensure quality assurance in course evaluation, peer evaluation and assessment. The following task should be performed by this department. ${ }^{1,5}$

( This department is responsible for the supervision of valid and reliable assessment system.

Q Self evaluation and quality assurance.

( Infrastructure of the Institute is reflecting the facilities for the students and the catered community.

Q There should be sufficient manpower in the Institute. (Trained faculties along with the subject specialist).

4 Activities related to teaching and learning should be standardized.

( To ensure structured assessment methods to appraise the attitudes, skills and knowledge which are properly aligned with learning strategies and learning outcomes.

( An objective and structured peer evaluation is incorporated in a regular feedback of students and alumni of the course.

( The university has to make arrangements for external examiners to conduct final university examinations.

How to determine the quality of undergraduate and post graduate institutes across Pakistan?

To determine the quality of undergraduate or post graduate medical education across Pakistan is judged through the student's outcomes by passing rate of Pakistani graduate physician in USMLE, national examination and other foreign licensure exams which is frequently measures in literature. ${ }^{15}$ Other way of determining the quality of undergraduate and post graduate education in Pakistan is the framework of accreditation standards in PMDC which is highlighted by following parameters.

4 Mission statement should be clearly displayed on the Institute's Website and well written in prospectus.

口 Outcomes of the undergraduate program should be well defined which explain the differentiation of the similar courses with other Institutes.

Q Curriculum document of the Institute will reflects the Institutional autonomy and academic freedom by policy document, implementation of curriculum, educational outcomes of the program, appropriate uses of curriculum resources and evidence based educational pedagogy.

u Curriculum design should address the national and international needs of the community and student should get the exposure with the patients in early years of education.

( Curriculum should be designed according to the framework proposed and prescribed by the International accreditation agencies.
( Half of the course will be based on the clinical sciences.

( Learning in clinical sciences should be structured and planned.

Q Quality improvement course content will be integrated from very initial years of undergraduate medical education.

( Mission and vision of the program should be aligned with the curriculum design; which should be outcome based, community oriented patient centered and will promote health and prevents disease.

Q To ensure the implementation of learning strategies which enhance active learning like PBL, student centered learning, self directed learning, e-learning, simulation, inter professional learning, peer learning. ${ }^{5}$

૫ Ensure organized and systemic learning in clinical settings by incorporating electives in curriculum.

( Educational content of the program should be developed with the consensus of the cohort of subject experts.

( Educational content should be aligned with core competencies of the accreditation agency, should be outcome based and should be relevant to the need.

૫ Educational content will highlighted the patient safety, professionalism and ethics, research, life saving skills, evidence based medicine, behavioral sciences and communication skills to produce safe healthcare providers.

( Integrated curriculum should be formulated by the subject experts from the clinical and basic sciences of that year of undergraduate program.

૫ Study skills, leadership skills should be the part of the educational content.

Q Curriculum management should be maintained and managed by the curriculum committee . $^{6}$

( Every undergraduate year should have separate study guides which express the details of learning objectives, mode of teaching, modes of assessment.

૫ Assessment ensures the balance between formative and summative assessment.

Q Wide range of assessment methods should be inculcated in educational content like portfolios, mini.

Q Assessment method should be compatible with the educational strategy and learning outcome.

口 Workplace based training should be structured and encouraged.

( Standard setting processes should be inculcated in examination items.

૫ There should be a student support program in every Institute like Mentoring.

( Students should comply the admission policy in concordance with the international standards.

Q To ensure the availability of student counselor in every Institute.

Q To ensure the presence of student representative in every committee related to student

u To maintain the quality standards, timely inspection is recommended.

Q The training of the future doctor is reflected by the 
deliberate practice instead of unstructured training for that every institute should ensure to make training electives more outcomes based and individual patient care.

( Availability of simulated patient is essential to practice as many times as needed to become skilled as cognitive psychological research on expertise evidenced that to become expert consistent practice is essential which is not possible on live patients.

- Continuous supervision and feedback should be provided to every student.

( Effective learning practice should be ensured by performing tasks repeatedly.

( Wide range of assessment methods should be inculcated in educational content to assess competencies like portfolios, $360^{\circ}$ feedback, and mini-clinical evaluation exercise with a positive attitude.

( To ensure the quality in research standards with relevant interdisciplinary collaboration.

( The national journals have to raise the standards of journals and so the original research.

\section{CONCLUSION:}

It is concluded that the quality document introduced by the PMDC is the true reflection of the world accreditation bodies WFME, WHO. By ensuring the true application of this quality document, Pakistan Medical and Dental Council will be able to compete with the International standards of medical education through competent future physicians.

\section{REFERENCES:}

1. Sallis E, editor. Total Quality Management in Education. London: Kogan Page Ltd; 2002

2. Blouin D, Tekian A. Accreditation of medical education programs: moving from student outcomes to continuous quality improvement measures. Academic Medicine. 2018;93(3):377-83.

3. van Zanten M, Norcini JJ, Boulet JR, Simon F.Overview of accreditation of undergraduate medical education programmes worldwide.Med Educ. 2008;42:930-937.
4. Cueto J Jr, Burch VC, Adnan NA, et al.Accreditation of undergraduate medicaltraining programs: Practices in ninedeveloping countries as compared with theUnited States. Educ Health (Abingdon).2006;19:207-222.

5. Boulet J, van Zanten M. Ensuring highquality patient care: The role of accreditation, licensure, specialty certification and revalidation in medicine. Med Educ.2014;48:75-86.

6. Davis DJ, Ringsted C. Accreditation of undergraduate and graduate medical education: How do the standards contribute to quality? Adv Health Sci Educ Theory Pract. 2006;11:305-313.

7. Al Alwan I. Is accreditation a true reflection of quality? Med Educ. 2012;46:542-544.

8. Biggs J. The reflective institution: Assuring and enhancing the quality of teaching and learning. Higher Educ 2001; 41:221-38

9. Schuwirth LW, van der Vleuten CP. Medical education: Challenges for educationalists. BMJ: British Medical Journal. 2006; 333(7567):544.

10. Memon AR. Research publications and education in Pakistani medical universities: Avoiding predatory journals and improving the quality of research. JPMA The Journal of the Pakistan Medical Association. 2017 Jun 1; 67:830.

11. Al-Shehri AM, Al-Alwan I. Accreditation and culture of quality in medical schools in Saudi Arabia. Med Teach. 2013;35(suppl 1):S8-S14.

12. Ten Cate O. Point: Global standards in medical educationWhat are the objectives? Med Educ. 2002;36:602-604.

13. Hogard E, Hunt D, Lichtenstein J. Quality Assurance in Medical Education: Accreditation and Teaching Standards in Australia, the USA, Canada and the UK. In Handbook of Quality Assurance for University Teaching 2018;(pp. 118132)

14. www.pmdc.org.pk/self assessment Performa

15. Stensaker B, Harvey L. Old wine in new bottles? A comparison of public and private accreditation schemes in higher education. Higher Educ Policy. 2006;19:65-85 